\title{
SEA USE MAP: GIS SUPPORTING MARINE AREA'S SUSTAINABLE DEVELOPMENT
}

\author{
MARCO MARCELLI ${ }^{1,2}$, FRANCESCO MANFREDI FRATTARELLI $^{1,2}$, VIVIANA PIERMATTEI $^{1,2}$, \\ SERGIO SCANU ${ }^{2}$, SIMONE BONAMANO ${ }^{1,2}$, DANIELE PIAZZOLLA ${ }^{2}$ \& GIUSEPPE ZAPPALÀ ${ }^{1,3}$ \\ ${ }^{1}$ Laboratory of Experimental Oceanology and Marine Ecology (LOSEM, DEB), University of Tuscia, Italy \\ ${ }^{2}$ Ocean Predictions and Applications Division, \\ Centro Euro-Mediterraneo sui Cambiamenti Climatici (CMCC), Italy \\ ${ }^{3}$ Institute for Biological Resources and Marine Biotechnologies, National Research Council (IRBIM-CNR), Italy
}

\begin{abstract}
The coastal zone is characterised by diversified physical and ecological conditions that allow the multiple use of natural resources. The overlap of very different uses generates conflict inducing habitat depletion and damage to natural systems. To face the problem of "conflict of use" of the coastal areas, we developed an integrated system as a working tool, the Sea Use Map (SUM), aimed to the characterization of the different values and uses of the marine resource, useful to explore further marine uses, such as suitable sites for marine renewable energy production, productive activities, etc. For this reason, the creation of an integrated GIS database, in which the information is conveyed in a geo-referenced system, is the necessary tool to support maritime spatial planning. The SUM of Italy is a key database, in which coastal uses are integrated with environmental data (seabed morphology, waves, currents, fauna, flora, etc.). Further integration between data and simulations of numerical models allows to define the most promising and ecologically acceptable areas for the introduction of new uses in view of the compatible development of the sea and marine resources. This paper presents a pilot application study in the coastal area between Capo Anzio and Tarquinia (Italy, Latium).
\end{abstract}

Keywords: GIS, marine ecosystem, marine renewable energy, siting, observing system, sea-use.

\section{INTRODUCTION}

With the Exclusive Economic Zone (EEZ) concept consolidation in the international jurisprudence, the continental shelf will be considered as a national boundary extension. In Italy, with more than $7,000 \mathrm{~km}$ of densely populated coasts, the continental shelf is always more affected by fundamental anthropogenic activities. The shelf area is characterized by the extraction of oil and of materials for industries of pottery, metallurgy, and glass; here fishery, mariculture, tourism are practiced; some areas are dedicated to marine biodiversity and environmental protection and to historical heritage protection [1].

In marine coastal areas a conflict among the different uses (both local and remote) occurs [2], [3], therefore it is necessary to minimize reciprocal impacts of the uses preserving at the same time all the structures and ecological processes. Indeed, ecological processes occurring in coastal areas are so important that their contribution to the value of the "natural capital" [4]-[6] is often higher than the terrestrial ones. Natural Capital evaluation is emerging as a fundamental tool to support the management of natural resources, representing the scientific basis for actions needed to enhance their conservation and sustainable use. Indeed, the achievement of the compatibility among their multiple uses, often in conflict in coastal areas, is a priority to avoid the increasing undesirable effects which threat both ecosystems and human health and well-being. Furthermore, the Millennium Ecosystem Assessment [1] assessed the consequences of ecosystems change for human well-being and, in particular, the analysis method has been centered on the linkages between "ecosystem services" (i.e., the benefits that people obtain from ecosystems) and human well-being. 
Within the Blue Growth strategy, the protection of marine ecosystems is considered a priority for the sustainable growth of marine and maritime sectors. To face this issue, the European MSP and MSFD directives [7], [8] strongly promote the adoption of an ecosystem-based approach; particular attention is paid to support monitoring networks that use Long-Term Ecological Research (L-TER) observations and integrate multi-disciplinary data sets and to define criteria for maritime space management. For all these reasons, there is the need to develop a methodology to analyze marine ecosystems properties in relationship within sea uses and climate change scenarios. An interdisciplinary approach including oceanography, ecology, geology, biology, meteorology is the basis of an integrated knowledge [9] able to support the decision through GIS and scenario's simulation.

This study aims to minimize the conflict among the different uses, creating a working tool able to support the decision, in order to select the best use for a specific marine area.

To face this necessity we developed a multi-layer GIS of coastal marine areas (Sea Use Map; SUM; Fig. 1), as a part of an integrated observing system, supported by a permanent monitoring system and able to interface a hierarchy of mathematical models, both for their validation and for the simulation of scenarios. This system takes into account both the different sea uses and the value of marine ecosystems, calculated on the basis of services and benefits produced by the different biocoenoses [2], [3].

The first prototype has been applied on the northern Latium coasts [10] in order to support the sustainable development of the Civitavecchia harbour.

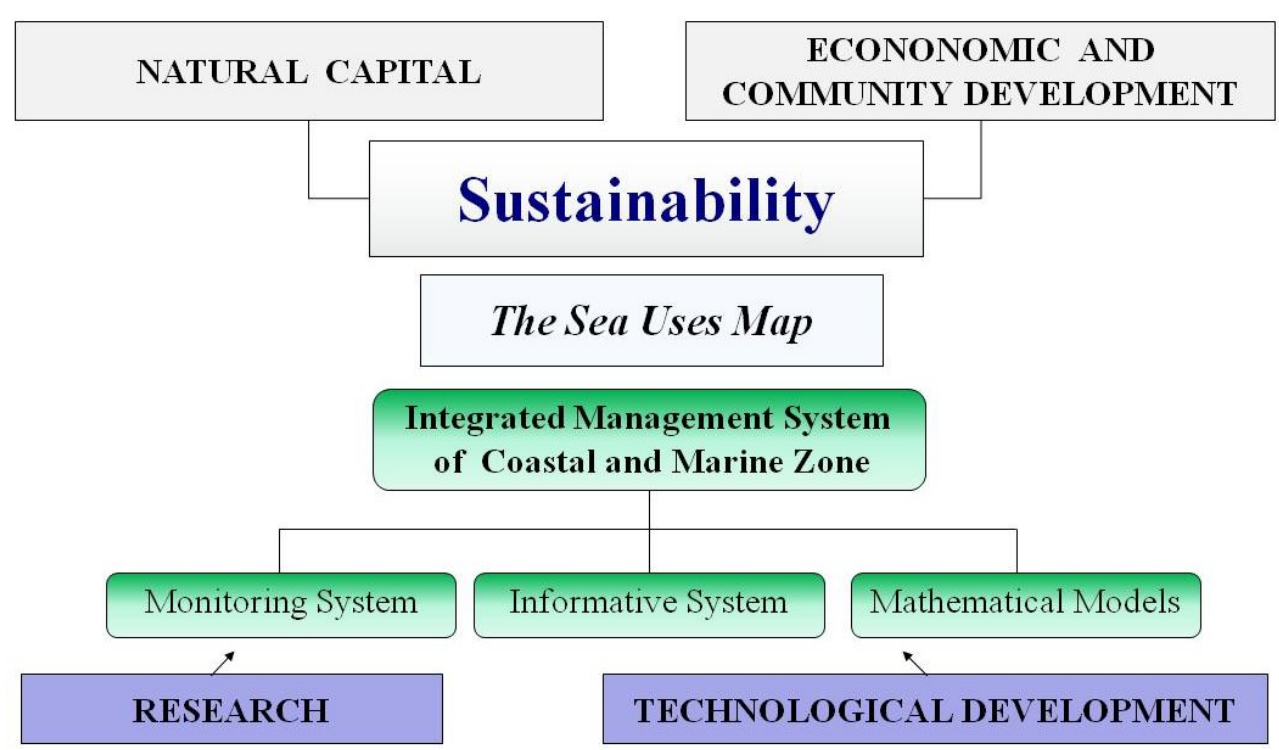

Figure 1: The Sea Use Map represents the connection tool between sustainable development and Natural Capital conservation on one hand and the technical tools to support the decision-making system on the other. The three modules (monitoring system, information system and numerical models) provide data and scenarios that overlap the uses allowing to guide the decision. Research and technological development fosters the three modules which remain up-todate and provide increasingly reliable information to support decision making. 
This tool supports a sustainable management of marine coastal areas, basically offering ecosystem benefits evaluation and pollution impacts minimization (Fig. 2), such as the selection of the best sites for the introduction of new uses or the identification of the coastal areas subjected to potential impacts. In synthesis, SUM is an ecosystem-oriented cartographic tool specifically designed to integrate the Civitavecchia Coastal Environment Monitoring System (C-CEMS) [10], consisting of: coastland maritime space uses, geomorphological and ecological features, mathematical modelling results, forecast scenarios, satellite observations, and in situ data from meteorological stations, wave buoys and $\mathrm{x}$-band radar, seawater fixed stations based on low cost technological developments providing physical and biological data, and making periodical surveys to characterize benthic biocoenoses and sediments.

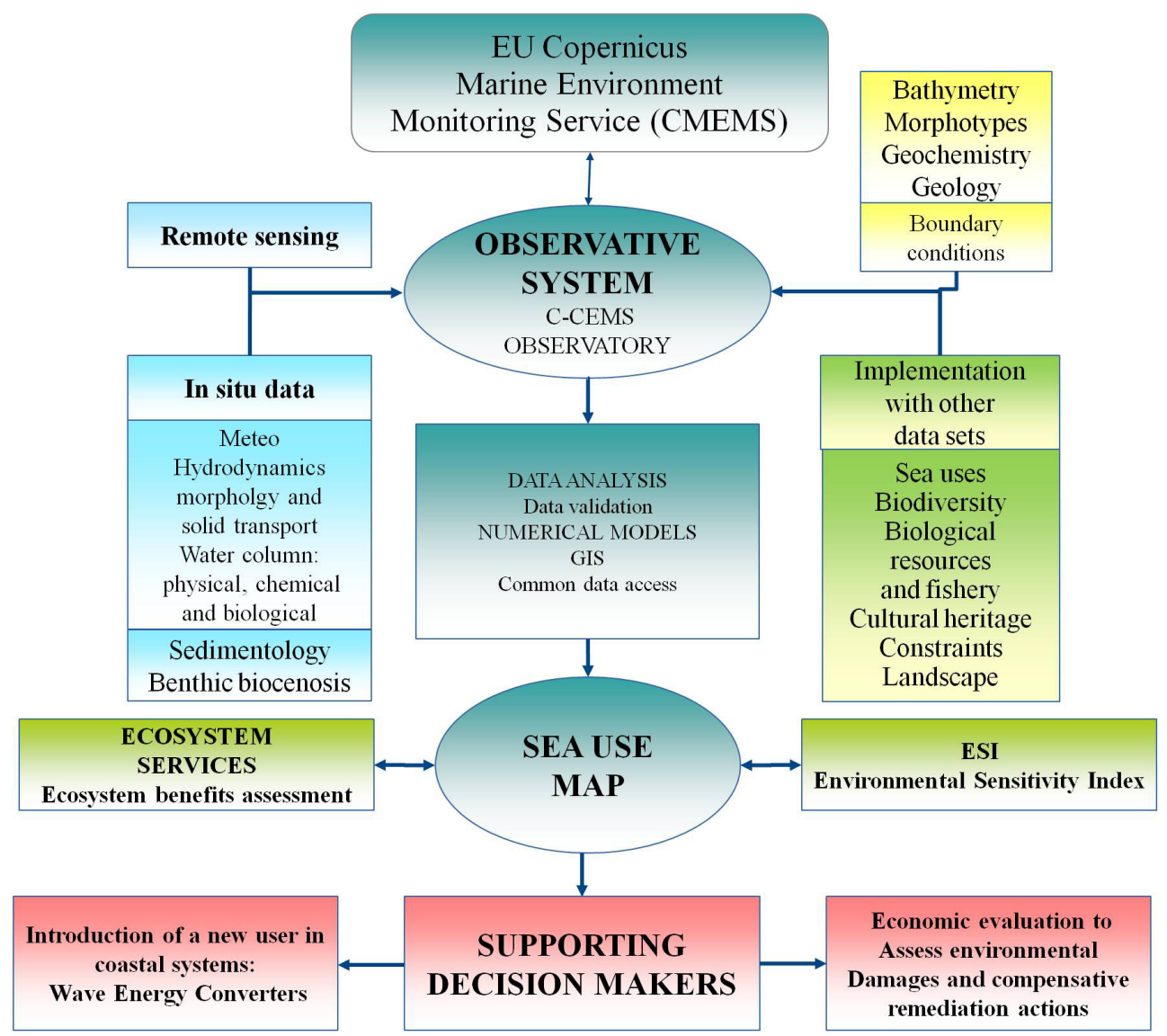

Figure 2: Diagram of components and goals of SUM as a scheme of an Integrated Observing System to be applied in the coastal and marine zones.

Our study focuses on the central and northern Latium (Italy) coastal area, characterized by high variability of marine and coastal environments, hosting important biodiversity hotspots (Posidonia oceanica, Reefs, protected species as Pinna nobilis and Corallium rubrum), historical heritage, and affected by the presence of the second biggest Italian river 
basin (Tiber River), of one of the most important port for cruise traffic in the Tyrrhenian Sea (The Port of Civitavecchia) [11], relevant industrial infrastructures, touristic features, and other minor ports (Anzio, Fiumicino, Santa Marinella).

The chosen approach aims to overcome the conflict of uses by integrating, in a system of tested numerical models and synoptic representations, information from field measurements and remote images. The integration of remote sensing data with field data has a critical importance because the latter represents the sea truth of the satellite synopsis (Fig. 3). This data integration allows a detailed analysis of the evolution in space and time of the effects due to the interactions between anthropogenic activities and natural ocean processes. The calibrated satellite data and the in situ data can in turn be assimilated into mathematical models through which it will be possible to obtain the representation of various scenarios. The present approach is therefore based on an overall strategy of detection, data processing and modeling, which will contribute to the evaluation of the space-time variation of the studied processes.

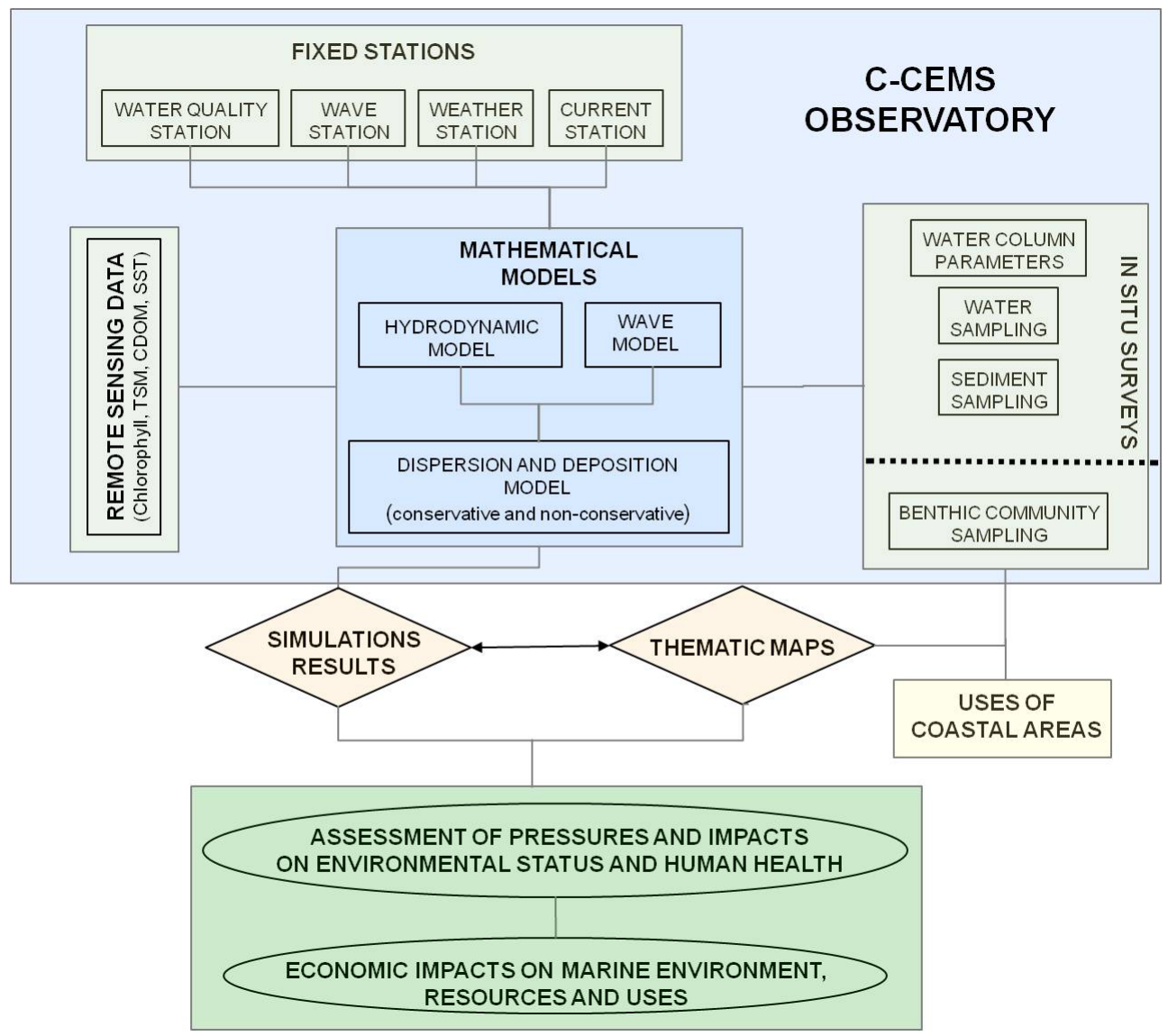

Figure 3: Main components of the Integrated Observing System "The Civitavecchia Coastal Environment Monitoring System" (C-CEMS) [applied to Civitavecchia port 10]. 
The SUM system is the result of an integration between environmental data collected by monitoring activities, socio-economic data coming from coastal zone uses, simulations by mathematical models and geographic information platform. It includes information needed for the planning of some activities connected to the coastal zone. This system can be divided into three main components (Fig. 1):

- Monitoring system;

- Informative system; and

- Mathematical models.

Within the environmental monitoring component can be detected different modules such as:

- coastal zone influence: this module inserts in the management system information about coastal morphotypes, water and solid outflows which characterize near shore marine zones, geology and geochemistry and about the land use in hinterland zones;

- sea bottom: this module integrates detailed information about morphological and geological characteristics of the seabed and information on the distribution and abundance of marine biota;

- marine weather: the marine weather data are useful to know the main forcing conditions on the sea interface such as wind, waves, tides and currents;

- water column: this module analyses physical, chemical and biological variables measured along the water column; and

- uses of marine and coastal areas: this module is crucial for planning coastal activities, to monitor and forecast their effects.

Management system's pillars are represented by previous data which will be gradually enriched with the new monitoring data collected.

In conclusion, this integrated system will be applied for the following purposes:

- management and data visualization;

- decision making;

- integrated database to support Environmental Impacts Study and to support authorization procedures for infrastructures realization;

- $\quad$ ante and post-operam studies;

- the simulation of different scenarios through mathematical models; and

- guidelines for monitoring plans.

\subsection{Description of the components}

The monitoring component is divided into different interdependent and flexible components, at different time and space scale. It is also included in MonGOOS system (see Fig. 4), and it can be easily and quickly integrated and/or modified on the basis of numerical modelling. Monitoring includes:

- experimental activities aimed at validating numerical models. In particular: oceanographic measurements of waves, currents, characteristics of the water column and sedimentological and solid transport measurements (including river inputs); 
- analysis of the morphodynamic sector; study of the liquid and solid flows of the Tiber river and the main tributaries of water;

- study of the variation of the shoreline in the short and long term through historical analysis of the shoreline and reconstruction of the submerged beach profiles (starting from 1990) and subsequent modifications using GIS; preparation and simulations through the model for the analysis of the shoreline evolution in the short and long term;

- $\quad$ preparation of the operating model and validation activities;

- characterization of the biotic compartment and of the chemical characteristics of the sediments;

- fixed measurement platforms (Acoustic Doppler Current Profiler - ADCP; wave buoys);

- autonomous measurement platforms in order to have more information, optimizing the sampling plan without increasing costs; and

- remote sensing from satellite (temperature, altimetry, chlorophyll a, Chromophoric Dissolved Organic Matter - CDOM, turbidity).

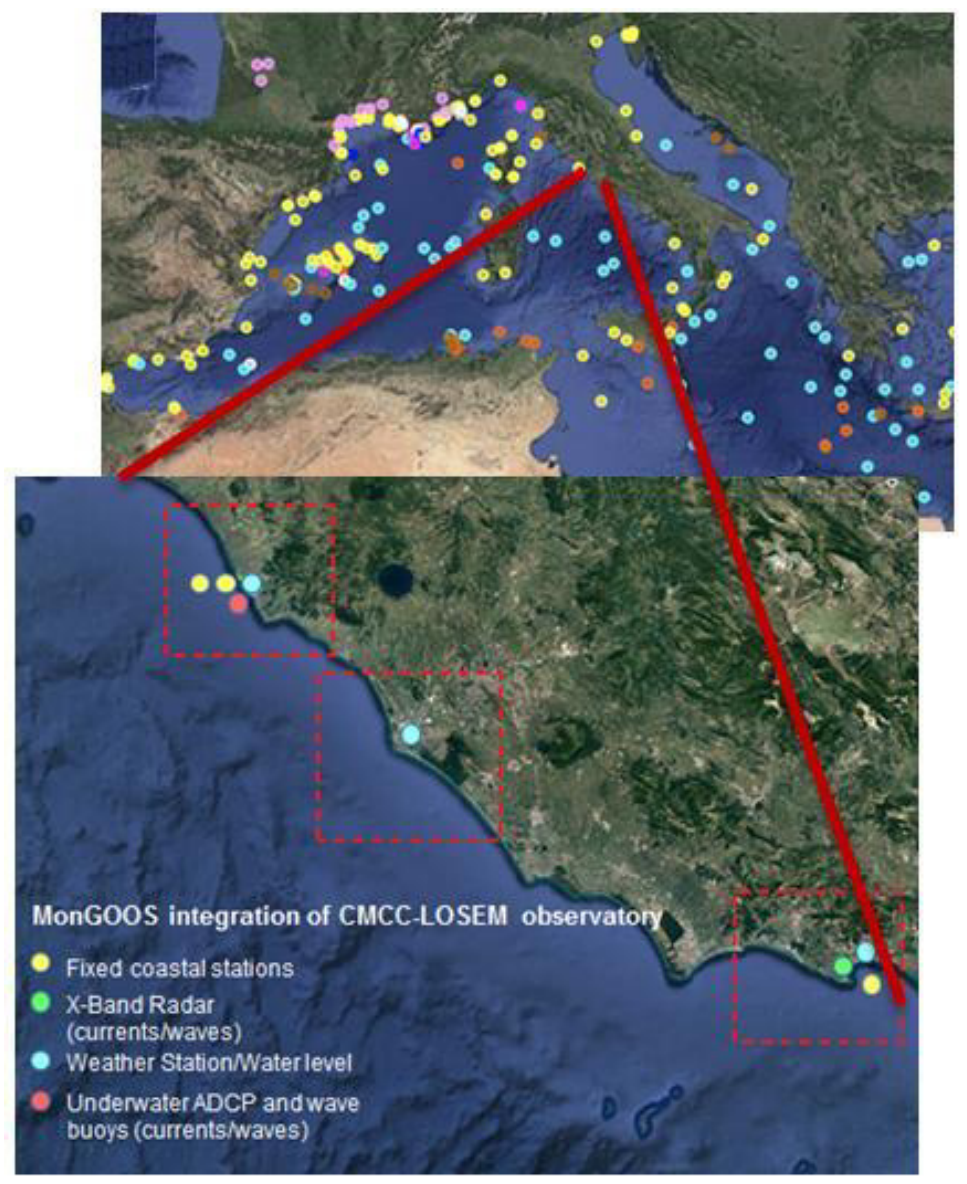

Figure 4: Fixed measurement stations and their location with respect to the MonGOOS system (http://www.mongoos.eu/). 
Below are reported some GIS representations and examples of use of the SUM in the coastal area of northern Latium (Italy). The continental component takes into account not only the fluvial contributions but also coastal morphotypes and land cover (Fig. 5). These
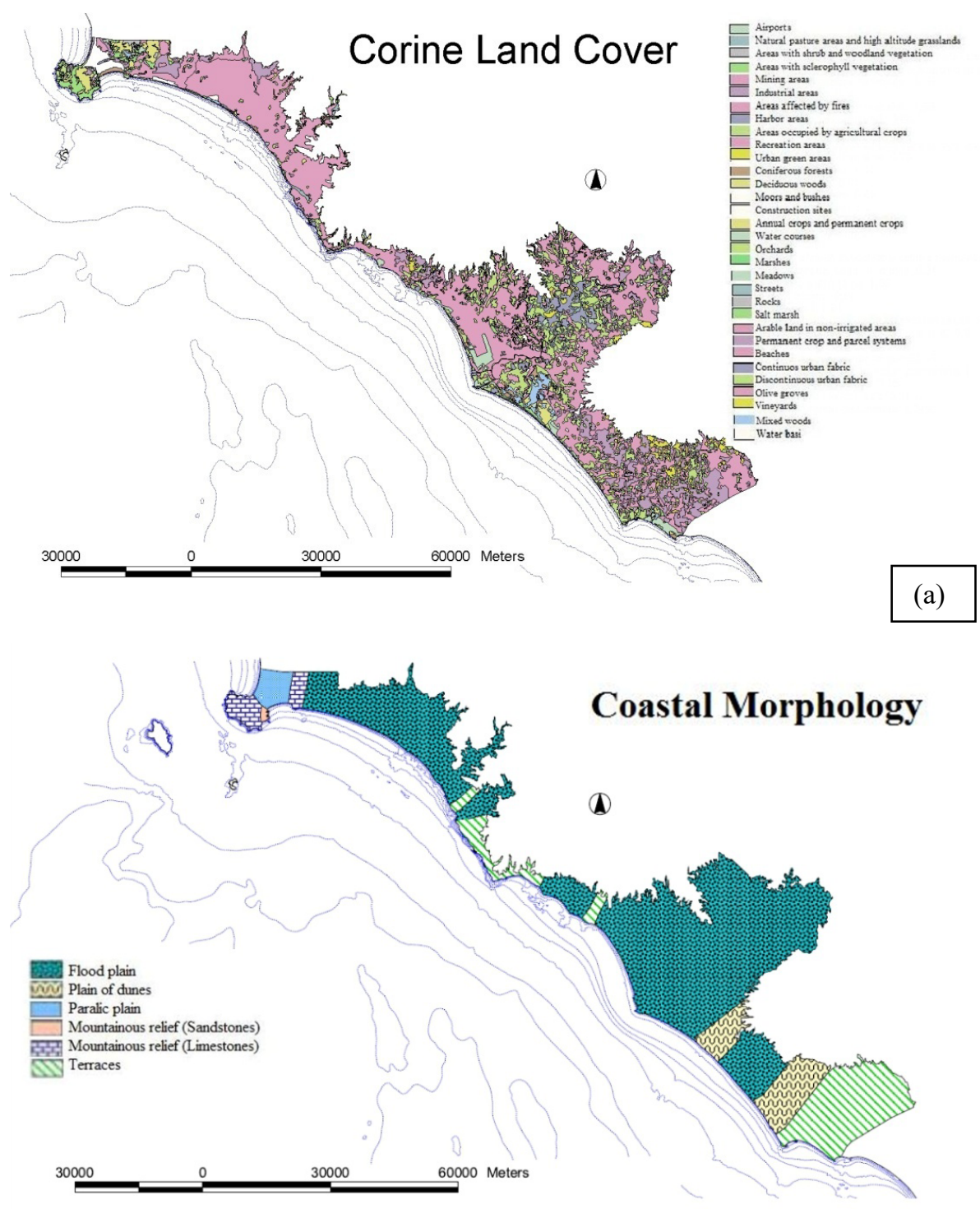

(b)

Figure 5: (a) Representation of the territory using the method of the European project Corine Land Cover for the preparation of the land use map. In this project, each element of the territory (pixel of $100 \mathrm{~m} \times 100 \mathrm{~m}$ ) is associated with a unique use based on a 3-level classification. Furthermore, the analysis of the territory is performed through remote sensing images; and (b) Representation of coastal morphotypes, based on the classification reported by Brondi et al. [14]. 
are useful for computing different climatic parameters and also to represent the cultural, recreational and social benefits useful to calculate the Cultural Ecosystem Services (CES).

The marine areas are represented by integrating a lot of information, from instrumental mapping of the seabed to the precise data coming from monitoring activities (e.g., bio-optic characterization of the water column, characterization of the benthic biocoenoses) (Figs 6 and 7). The integrated tool SUM therefore allows us to weigh the uses of the sea and their effects on the ecosystems. For example, Fig. 8 shows the use of SUM in relation to fishing activity. For fishing data, a three-digit code is proposed, each of them relates to a kind of fishing: the first on the left represents trawling, the one in the centre represents small-scale fishing and the one on the right indicates shellfish fishing. Each digit assumes the value 0 if that activity is not practiced, the value 1 in the opposite case and the values $2,3 \ldots 9$ depending on the type of fishing performed by the 1, 2 ... fleet (Fig. 8).

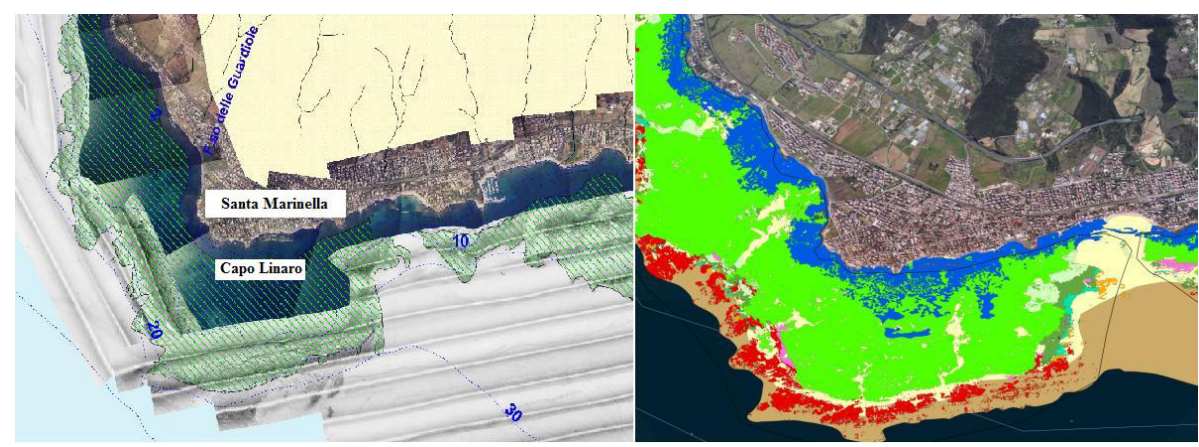

Figure 6: (Left) GIS representation of Posidonia oceanica meadow integrating several survey methods and (right), GIS classification of biocoenoses.

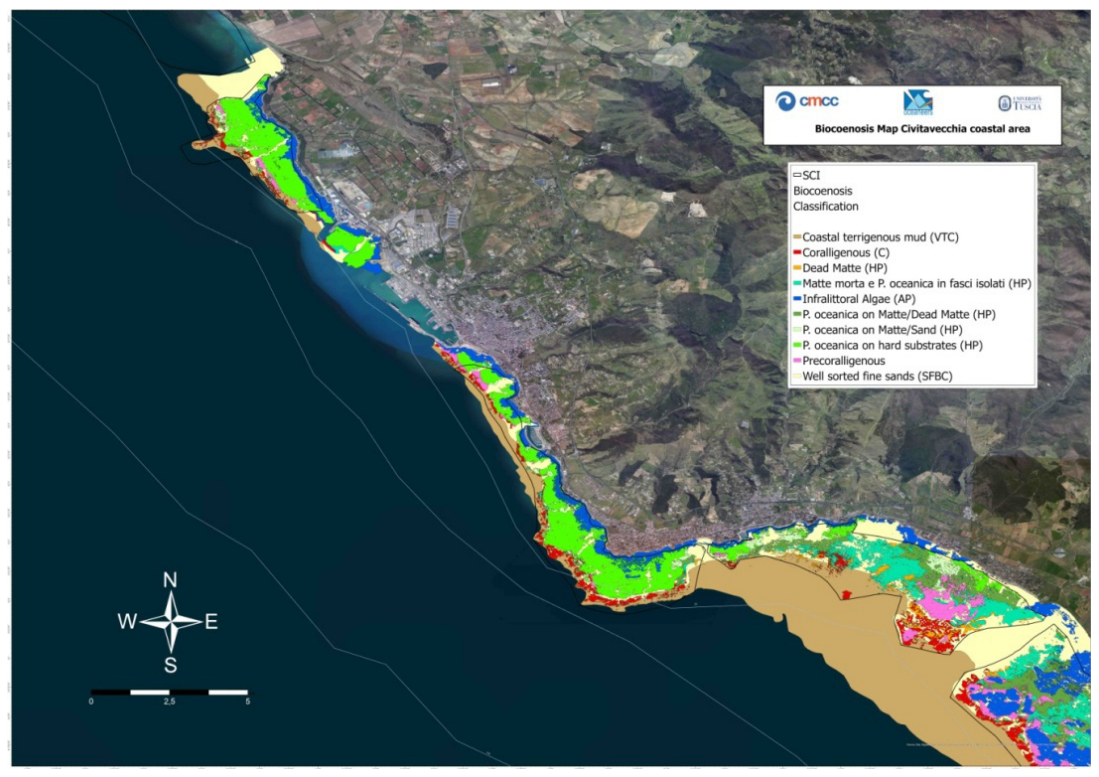

Figure 7: GIS representation of benthic biocoenoses in the northern Latium coastal area. 


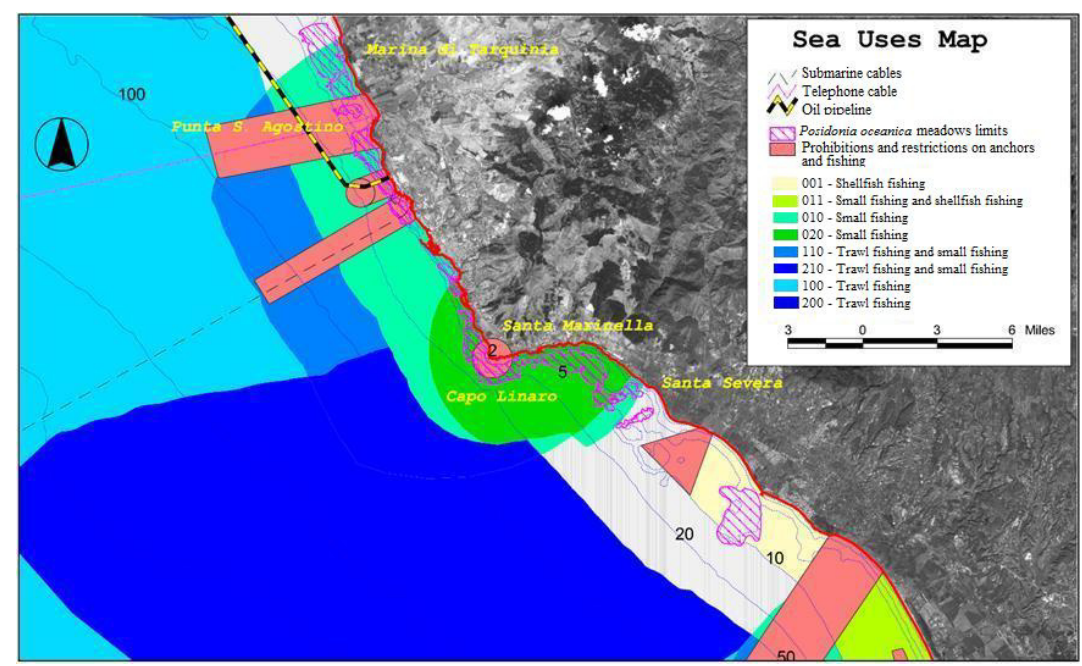

Figure 8: Fishing activity analysed using SUM in the coastal area of Civitavecchia (Northern Latium, Italy).

\subsection{Characteristics of the numerical models}

Current velocity and wave propagation are obtained by numerical models. Here we present preliminary results obtained by simulations between S. Agostino and Capo Linaro. In particular, current velocity field is simulated by ADvanced CIRCulation model (ADCIRC [12]) and wave field is simulated by the STeady-state spectral WAVE model (STWAVE [13]). ADCIRC model solves the motion equations for a moving fluid on a rotating earth. Those equations are formulated by using the traditional hydrostatic pressure and Boussinesq approximations; they are discretized in space by using the finite elements method, and in time by using the finite differences method. The computational domain covers the coastal area for about $150 \mathrm{~km}$. Because small errors could occur near the boundaries, the study area was located far from the model edges. The fine element mesh shows a resolution ranging from $30 \mathrm{~m}$ in the areas surrounding Civitavecchia port to about $5 \mathrm{~km}$ near the off-shore boundary positioned about $30 \mathrm{~km}$ from the coast.

The current velocities, calculated by the model, are obtained combining the general circulation current of Tyrrhenian Sea (as boundary condition), and the south-east wind $\left(\right.$ Scirocco $\left.-135^{\circ} \mathrm{N}\right)$ with an intensity of $10 \mathrm{~m} / \mathrm{s}$.

The Scirocco wind increases the current velocity to the south $(0.5 \mathrm{~m} / \mathrm{s})$, at Capo Linaro, and to the north $(0.3 \mathrm{~m} / \mathrm{s})$ near S. Agostino (Fig. 9) while in Civitavecchia harbour the velocities are very slow.

The wave field is obtained by STWAVE model, which is a finite-differences model solving the wave dispersion equation and take into account of refraction, shoaling, diffraction and radiation stress. The computational domain extends from S. Agostino in the north to Capo Linaro in the south. The offshore boundary is located at $70 \mathrm{~m}$ depth. The model grid presents a constant resolution with the element size of $50 \mathrm{~m}$. The diffraction intensity is equal to 1 and the bed friction is assigned to 0.005 and assumed spatially constant in the entire domain. The wave field is obtained by wave spectrum calculated with wave height of $3 \mathrm{~m}$ and direction of $225^{\circ} \mathrm{N}$. 


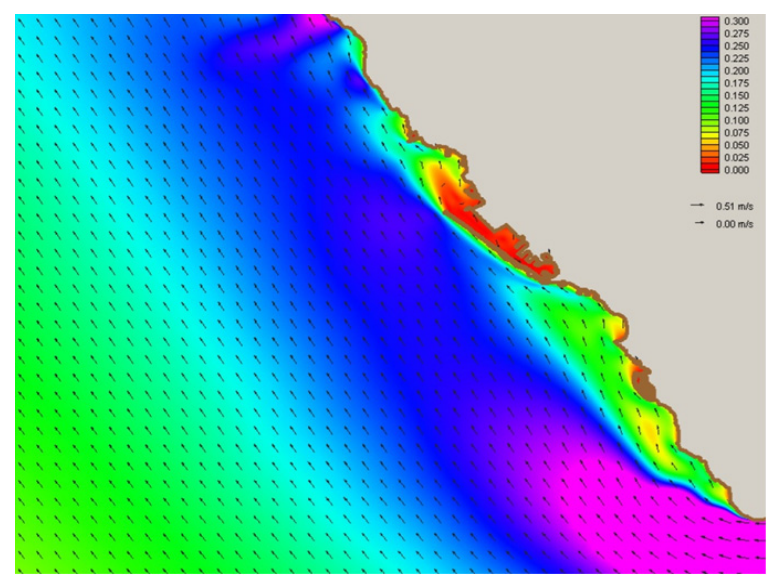

Figure 9: Velocity field $(\mathrm{m} / \mathrm{s})$ obtained by general circulation current of the Tyrrhenian Sea and by Scirocco wind $\left(135^{\circ} \mathrm{N}\right)$. Purple areas represent high velocity while those in red represent low velocity.

Fig. 10 left shows the wave propagation towards the coast and the areas where wave energy is high (dark blue zone). Fig. 10 right represents the velocity field obtained by radiation stress calculated from a wave height of $3 \mathrm{~m}$ and a direction of $225^{\circ}$. The results of the simulation show an increase in velocity $(0.4 \mathrm{~m} / \mathrm{s})$ in the northern part of the study area.
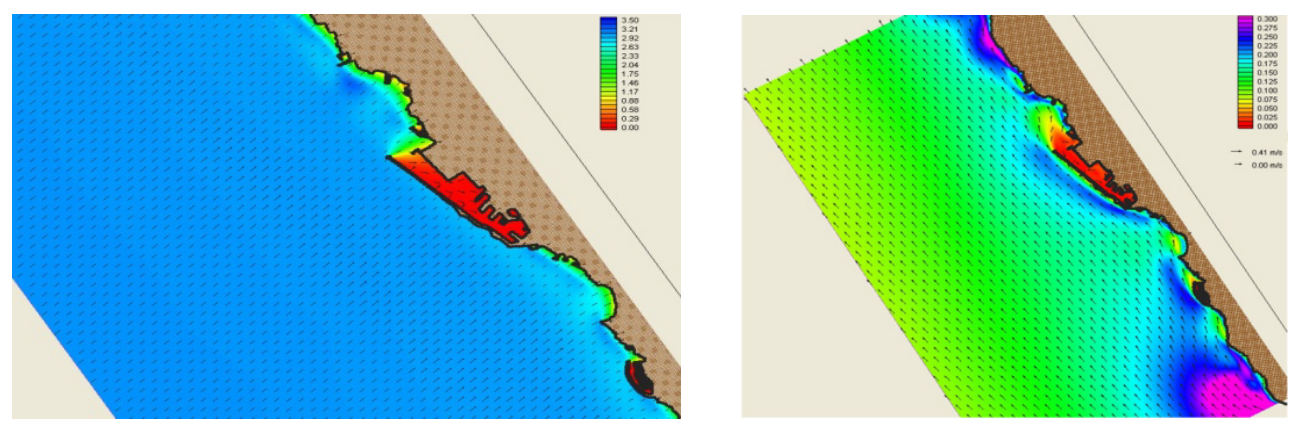

Figure 10: (Left) Wave field obtained from STWAVE simulation. Blue areas represent high wave elevations while those in red represent low wave elevations. (Right) Velocity field obtained by radiation stress gradient. Purple areas represent high velocity while those in red represent low velocity.

\section{DISCUSSION AND CONCLUSIONS}

Coasts are extremely sensitive areas, characterized by the presence of multiple human activities due to the simultaneous presence of physical and ecological conditions advantageous for the multiple use of natural resources. To address this problem, a strategy based on the best evaluation of the conditions is needed, which determine the choice of the best use of a specific area. This strategy must be based on the best evaluation of the 
conditions, which determine the choice of the best use of a specific area. The choice takes into account all the components of the system and the effects that come from the choice.

Some problems can arise and the perception of these problems can be:

- $\quad$ oriented by a resource or by a specific status of the resource (regardless of the use of the resource, like littoral dynamic, rare species, whole ecosystems) and

- uses oriented: threshold values of some descriptors can damage or preclude a specific use (the value can be or not arranged by normative references, e.g., "no bathing" areas).

Both the perceptions, uses and resources, must be considered in the planning action.

To cope with the described problem, we have developed the Sea-Use-Map (SUM), an integrated system and work tool. The SUM is the only instrument which allows both to analyse all the components of a system and to weigh uses conflict and effects.

Some problems remain: the analyses of the stored information and the choice of the analytical instruments to be integrated in the SUM, in order to provide numerical index for the decision support. Until now the choice is oriented to the integration of decision making models, which seem to be pointed to this approach.

\section{REFERENCES}

[1] Millennium Ecosystem Assessment (MA), Overview of the millennium ecosystem assessment. www.millenniumassessment.org/en/About.html. Accessed on: 15 Oct. 2018.

[2] Marcelli, M., Scanu, S., Frattarelli, F.M., Mancini, E. \& Carli, F.M., A benthic zonation system as a fundamental tool for natural capital assessment in a marine environment: A case study in the Northern Tyrrhenian Sea, Italy. Sustainability, 10(10), p. 3786, 2018.

[3] Marcelli, M., L'importanza dello studio della dinamica litoranea nella progettazione portuale. Chiron, 1, pp. 10-12, 2003.

[4] Costanza, R. et al., The value of the world's ecosystem services and natural capital. Nature, 387(6630), pp. 253-260, 1997.

[5] Costanza, R., Pérez-Maqueo, O., Martinez, M.L., Sutton, P., Anderson, S.J. \& Mulder, K., The value of coastal wetlands for hurricane protection. Ambio, 37(4), pp. 241-248, 2008.

[6] Costanza, R. et al., Changes in the global value of ecosystem services. Global Environmental Change, 26, pp. 152-158, 2014.

[7] EC Directive 2014/89/EU of the European Parliament and of the Council of 23 July 2014 establishing a framework for maritime spatial planning, 2014.

[8] EC Directive 2008/56, Official Journal of the European Union, 164(25 Jun. 2008), pp. 19-40, 2008.

[9] Brondi, A., Di Maio, A. \& Marcelli, M., Principi logici per il monitoraggio dell'ambiente costiero. Geologia dell'Ambiente, 2, pp. 19-35, 2008.

[10] Bonamano, S. et al., The Civitavecchia Coastal Environment Monitoring System (CCEMS): A new tool to analyze the conflicts between coastal pressures and sensitivity areas. Ocean Science, 12(1), pp. 87-100, 2016.

[11] Piazzolla, D. et al., Microlitterpollution in coastal sediments of the northernTyrrhenian Sea, Italy: Microplastics and fly-ash occurrence and distribution. Estuarine, Coastal and Shelf Science, 241, p. 106819, 2020. 
26 Computational Methods and Experimental Measurements XX

[12] Luettich, R.A. \& Westerink, J.J., AADvance CIRCulation model for oceanic, coastal and estuarine waters. Manual, 2000.

[13] Smith, J.M., Sherlock, A.R. \& Resio, D.T., STWAVE: Steady-state spectral wave model. User's Manual for STWAVE, Version 3.0, ERDC/CHL SR-01-1, Coastal and Hydraulics Laboratory, 2001.

[14] Brondi, A., Benvegnù, F., Ferretti, O. \& Anselmi, B., Classificazione geomorfologica delle coste italiane come base per l'impostazione di studi sulla contaminazione marina. Proceedings of the Italian Association of Oceanology and Limnology (AIOL), Sorrento, 1982. 